\title{
Effects of Salinity on Germination Behaviour of Two Paddy Landraces Grown in Chakrata, Dehradun, Uttarakhand, India
}

\author{
Ranbeer Singh Chauhan ${ }^{1}$, J.S. Chauhan ${ }^{1}$, A.S. Rawat and Dinesh Singh Rawat ${ }^{2} *$ \\ ${ }^{I}$ Department of Seed Science and Technology, HNB Garhwal University, \\ Srinagar (Garhwal) - 246174, Uttarakhand, India \\ ${ }^{2}$ Central National Herbarium, Botanical Survey of India, Howrah -711103, West Bengal, India
}

\begin{abstract}
Germination ability of seeds varies significantly amongst different varieties of same crop when exposed to the stress. Paddy (Oryza sativa L.) is known to be highly sensitive to salinity during germination and young seedling stages. Present study was aimed to observe the effects of six salinity concentrations $(0 \%, 0.1 \%, 0.5 \%, 1 \%$, $1.5 \%$ and $2 \%$ ) on the germination behaviour of two paddy landraces (Chenaphool and Gyasu), frequently grown in Chakrata area of district Dehradun, Uttarakhand. Salinity $(>0.1 \%)$ was inversely related to final germination percentage, germination energy, plumule dry weight, plumule length, radical dry weight, radical length and speed of germination. Chenaphool landrace showed higher germination and growth (plumule and radical) at $0 \%$ salinity (control), while Gyasu landrace at $0.1 \%$ salinity level.Dry weight percentage reduction increased with increasing salinity level, while negative correlation was observed between salinity and salt tolerance index and seed vigour index for both the varieties. The study concluded that the long grained, irrigated landrace Chenaphool was more sensitive to salinity in comparison to short grained, non-irrigated landrace Gyassu. Lower salinity conditions have no adverse effects on the germination behaviour of Gyasu landrace.
\end{abstract}

Keywords : Germination behaviour, landraces, paddy, salinity, seed

\section{Introduction}

India is the largest paddy (Oryza sativa L.) growing country. Approximately 44.6 million ha paddy is grown annually under 4 major agro-ecosystems: irrigated (21 million ha), rainfed lowland (14 million ha), rainfed upland (6 million ha) and flood-prone ( 3 million ha) which contribute $67.3 \%, 22.9 \%, 6.6 \%$ and $3.3 \%$ in total rice production respectively (Sati 2005). Paddy is grown up to $2300 \mathrm{~m}$ a msl in hills of northern India but there is a wide gap between the productivity of hills and plains, low temperature being main constraint at higher altitude. Paddy apart from being a source of food is intimately related to religious, cultural and social functions of the life of hill peoples. It also provides feed for cattle, thereby, reducing pressure on grazing land and forests. Thus, paddy helps to balance the delicate ecosystem of Himalayas, where fodder scarcity is more acute (Siddiq et al. 2009). In hill regions, farmers prefer to grow the paddy landraces adapted to rainfed terraced lands.

Uttarakhand, one of the Himalayan states of India is well known for its rich natural resources. It comprises of two distinct physiographic regions viz. hills (86.07\%) and plain (13.93\%). Larger part is characterized by a difficult terrain, undulating topography, remote and inaccessible villages, sparse population, tiny land holdings, agriculture-based economy and weak infrastructure (Negi et al. 2009). Agriculture based activities are the main source of livelihood for the major population (Javed and Khan, 1995; Kumar et al., 2010). About $75-90 \%$ population of the state is engaged either in the main occupation of agriculture or its allied practices, dominated by traditional subsistence cereal farming (Maikhuri et al., 2011; Nasim et al., 2008).

*Corresponding author (Email: dsrwt7@rediffmail.com) 
Fragmented and small land holdings, sloping lands and rainfall-dependent farming aggravated by migratory grazing lead to very poor yields.

Cultivated crops are exposed to various environmental stresses such as salt, drought and freezing. Salinity is the second most widespread soil problem in rice growing countries after drought (Bliss et al 1986) and is considered as a serious constraint in increasing rice production worldwide (Lutts, 1996). In Asia alone, 21.5 million ha of land area is thought to be salt-affected. India has 8.6 million ha of such area which constitutes a major part of soil problem throughout the country (Chandra et al 2008). Most of the rice varieties are extremely sensitive to salinity during germination and young seedling stages (Prisco and Vieira 1976; Michael et al 2004). Low concentrations of salt suppress plant growth while higher concentration can cause death (Hakim et al 2010). Under saline conditions, germination ability of seed varies from one crop to another, even significant variation was observed amongst different varieties of the same crop (Ruan et al 2002; Sahi 2006). It is necessary to identify the sensitivity and tolerance level of a variety at early seedling stages for successful crop production in a saline environment. Some studies are available on this aspect from India (Khan et al 1997) however virtually no attempts have been made on indigenous landraces of Uttarakhand. The present study was aimed to assess seed germination and subsequent seedling growth $v i s-\grave{a}$-vis salinity tolerance of two rice landraces from Uttarakhand hills.

\section{Materials and Methods}

The study evaluated two paddy landraces (locally identified) viz. Chenaphool (China-4) and Gyasu, commonly grown in the Chakrata area of Dehradun district in Uttarakhand. The voucher specimens of Chenaphool (GUH 20984) and Gyasu (GUH 20985) have been submitted in the Herbarium of Garhwal University (GUH). Chenaphool is cultivated under irrigated conditions and has relatively higher yield potential than Gyasu grown under non-irrigated conditions. The comparative morphological features of the seeds of these two landraces are presented in Table 1. A major part of the cultivated land in Chakrata region is unirrigated. However, the land along the streams and rivers sites receive irrigation water from a well-established network of canals and thus these are considered as irrigated lands. Seeds of each landrace were collected directly from farmers $(n=10)$ and composite samples were prepared by mixing seeds of respective landraces.

Table 1. Seed morphology of Chenaphool and Gyassuice variety

\begin{tabular}{lll}
\hline \multirow{2}{*}{ Parameters } & \multicolumn{2}{c}{ Rice variety } \\
\cline { 2 - 3 } & Chenaphool & Gyassu \\
\hline Density $\left(\mathrm{gmml}^{-1}\right)$ & $0.033 \pm 0.004$ & $0.034 \pm 0.002$ \\
Length (mm) & $8.66 \pm 1.24$ & $6.71 \pm 1.14$ \\
Moisture content (\%) & $9.92 \pm 1.84$ & $9.7 \pm 1.62$ \\
Physical purity (\%) & $99.79 \pm 0.64$ & $99.76 \pm 0.56$ \\
Weight (g) & $24.82 \pm 1.62$ & $30.55 \pm 2.32$ \\
Width (mm) & $3.01 \pm 0.15$ & $3.36 \pm 0.12$ \\
\hline
\end{tabular}

The physical purity, seed moisture content, germination test, seed weight, density, length and width of seeds were analyzed (Anonymous 2008). Prior to the experiments, all the glassware were sterilized by autoclaving while seeds were surface sterilized by $1 \%$ sodium hypochlorite $(\mathrm{NaOCl})$. Seed germination bioassay was used to test the effect of salinity. The soil solutions i.e. $0.1 \%$, $0.5 \%, 1 \%, 1.5 \%$ and $2 \%$ along with a control $(0 \% \mathrm{NaCl})$ were prepared. Four replicates per treatment each containing 25 seeds were kept for germination. The petri dishes were placed in seed germinator at $25 \pm 1{ }^{\circ} \mathrm{C}$ temperature, $62 \pm 1 \%$ relative humidity and 12 hour photoperiod for 14 days. The seeds were kept moist regularly either by applying distilled water (control) or with respective $\mathrm{NaCl}$ solution.

The number of seeds germinated was counted daily up to 14 days under each treatment to record germination percentage. Final germination percentage (FGP), germination energy (GE) and speed of germination (SG) were calculated as per Ellis and Robert (1981) and Ruan et al. (2002). Plumule length (PL) and radical length (RL) was measured by selecting 5 seedlings from each treatment 
randomly at the time of final count. Plumule dry weight (PDW) and radical dry weight (RDW) was recorded immediately after oven drying at $80^{\circ} \mathrm{C}$ for 24 hours. Dry weight percentage reduction (DWPR), salt tolerance index (STI) and seed vigour index(SVI) were calculated with the following formula:

$$
\begin{aligned}
& \text { DWPR }(\%)=100 \times\left[1-\left(\text { Dry weight }{ }_{\text {salt stress }} / \text { Dry weight }{ }_{\text {control }}\right)\right] \\
& \text { STI }(\%)=100 \times\left(\text { Total dry weight } \text { salt stress } \text { Total dry weight }{ }_{\text {control }}\right) \\
& \text { SVI }(\%)=\text { Germination percentage } \times \text { Means of seedling length }(\text { root }+ \text { shoot }) / 100
\end{aligned}
$$

\section{Results and Discussion}

In Uttarakhand, the farmers in the focal area traditionally use landraces of paddy having ability to withstand climatic exigencies, possessing many vital qualities such as pest resistance, drought-resistance, high protein content, flavour, etc. (Bisht et al 2007). The seeds of the studied landraces, Chenaphool (irrigated) and Gyasu (non-irrigated), were found to be almost similar with respect to density, moisture content and physical purity (Table 1). Land races were significantly distinct from each other in respect of seed length, seed width and seed weight. Seeds of Chenaphool $(8.66 \pm 1.24 \mathrm{~mm})$ were longer than Gyasu $(6.71 \pm 1.14 \mathrm{~mm})$, while seed weight of Gyasu was more $(30.55 \pm 2.32 \mathrm{~g})$ in comparison to Chenaphool $(24.82 \pm 1.62 \mathrm{~g})$.

\section{Effects of Salinity on Germination}

Germination initiated on the fourth day after sowing and differences were noticed under different saline stress conditions from $5^{\text {th }}$ day onwards. FGP, GE and SG were higher under controll conditions for Chenaphool landrace (Table 2). Gyasu landrace showed highest FGP, GE and SG at $0.1 \%$ salinity stress (Table 3 ). In Chenaphool, FGP, GE and SG gradually decreased with increasing salinity from $0.1 \%-0.5 \%$, and an abrupt fall at $(1 \%-2 \%)$. Detrimental effects of higher salinity levels occur because of osmotic stress (Bliss et al. 1986;Almansouri et al 2001) and specific ion toxicity (Hampsonand Simpson, 1990). Salinity showed significant negative correlation with FGP, GE and SG in both the landraces (Table 4 and 5). Negative effects of salinity on FGP, GE (Mondal et al 1988) and SG in paddy were also reported by some earlier workers (Khan et al. 1997, , Hakim et al.2010, Vibhuti et al., 2015).

Table 2. Effects of salinity on different physiological attributes of Chenaphool rice variety

\begin{tabular}{lllllll}
\hline \multirow{2}{*}{ Parameter* } & \multicolumn{9}{c}{ Salinity level(\%) } & & \\
\cline { 2 - 7 } & $\mathbf{0}$ & $\mathbf{0 . 1}$ & $\mathbf{0 . 5}$ & $\mathbf{1 . 0}$ & $\mathbf{1 . 5}$ & $\mathbf{2 . 0}$ \\
\hline FGP (\%) & $98.75 \pm 0.48$ & $97.5 \pm 0.71$ & $97.5 \pm 1.81$ & $88.75 \pm 2.19$ & $82.5 \pm 0.96$ & $21.25 \pm 1.38$ \\
GE (\%) & $98.75 \pm 0.64$ & $97.5 \pm 0.81$ & $97.5 \pm 0.74$ & $62.5 \pm 0.54$ & $7.5 \pm 0.48$ & Nil \\
PDW (g) & $5.6 \pm 0.71$ & $4.8 \pm 0.72$ & $3.7 \pm 0.24$ & $1.5 \pm 0.10$ & $0.6 \pm 0.13$ & Nil \\
PL (cm) & $9.49 \pm 0.91$ & $6.16 \pm 0.78$ & $6.12 \pm 0.42$ & $2.1 \pm 0.26$ & $0.74 \pm 0.21$ & $0.1 \pm 0.01$ \\
RDW (g) & $4.8 \pm 0.82$ & $3.4 \pm 0.45$ & $2.8 \pm 0.26$ & $0.3 \pm 0.12$ & $0.2 \pm 0.1$ & Nil \\
RL (cm) & $7.47 \pm 0.68$ & $5.14 \pm 0.30$ & $4.57 \pm 0.54$ & $1.62 \pm 0.35$ & $0.54 \pm 0.30$ & $0.1 \pm 0.20$ \\
SG (\%) & $9.87 \pm 0.85$ & $9.75 \pm 0.77$ & $8.77 \pm 0.62$ & $4.5 \pm 0.65$ & $2.5 \pm 0.67$ & $0.65 \pm 0.21$ \\
\hline
\end{tabular}

*FGP=final germination percentage, GE=germination energy, PDW=plumule dry weight, $\mathrm{PL}=$ plumule length, $\mathrm{RDW}=$ radical dry weight, $\mathrm{RL}=$ radical length and $\mathrm{SG}=$ speed of germination. 
Table 3. Effects of salinity on different physiological attributes of Gyassu rice variety

\begin{tabular}{|c|c|c|c|c|c|c|}
\hline \multirow{2}{*}{ Parameters } & \multicolumn{6}{|c|}{ Salinity level (\%) } \\
\hline & $\mathbf{0}$ & 0.1 & 0.5 & 1.0 & 1.5 & 2.0 \\
\hline FGP (\%) & $45 \pm 0.82$ & $47.5 \pm 0.76$ & $27.5 \pm 1.26$ & $21 \pm 1.30$ & $17.5 \pm 1.14$ & $12.5 \pm 1.56$ \\
\hline GE (\%) & $35 \pm 0.71$ & $45 \pm 0.66$ & $25 \pm 0.55$ & $20 \pm 0.63$ & $10 \pm 0.48$ & Nil \\
\hline PDW (g) & $6.3 \pm 0.68$ & $8.4 \pm 0.62$ & $4.4 \pm 0.42$ & $3.4 \pm 0.24$ & $1.1 \pm 0.13$ & Nil \\
\hline PL (cm) & $9.61 \pm 0.58$ & $10 \pm 0.60$ & $5.22 \pm 0.34$ & $3.53 \pm 0.28$ & $1.13 \pm 0.15$ & $0.26 \pm 0.02$ \\
\hline RDW (g) & $6.5 \pm 0.56$ & $5.5 \pm 0.54$ & $4 \pm 0.35$ & $1.5 \pm 0.43$ & $0.4 \pm 0.13$ & Nil \\
\hline $\mathrm{RL}(\mathrm{cm})$ & $9.17 \pm 0.74$ & $8.39 \pm 56$ & $5.58 \pm 0.51$ & $2.54 \pm 0.41$ & $0.81 \pm 0.36$ & $0.13 \pm 0.12$ \\
\hline SG (\%) & $3.5 \pm 0.51$ & $3.5 \pm 0.77$ & $1.91 \pm 0.48$ & $1.56 \pm 0.42$ & $0.7 \pm 0.29$ & $0.41 \pm 0.17$ \\
\hline
\end{tabular}

Table 4. Correlation between different physiological attributes of Chenaphool rice

\begin{tabular}{|c|c|c|c|c|c|c|c|}
\hline & Salinity & FGP & GE & PDW & PL & RDW & RL \\
\hline FGP & $-0.836^{*}$ & 1.00 & & & & & \\
\hline GE & $-0.961^{* *}$ & 0.787 & 1.00 & & & & \\
\hline PDW & $-0.977^{* *}$ & 0.723 & $0.928^{* *}$ & 1.00 & & & \\
\hline PL & $-0.943^{* *}$ & 0.687 & $0.903^{*}$ & $0.982^{* *}$ & 1.00 & & \\
\hline RDW & $-0.921^{* *}$ & 0.625 & $0.858^{*}$ & $0.981^{* *}$ & $0.987^{* *}$ & 1.00 & \\
\hline RL & $-0.949^{* *}$ & 0.681 & $0.902^{*}$ & $0.989^{* *}$ & $0.998^{* *}$ & $0.991^{* *}$ & 1.00 \\
\hline SG & $-0.988^{* *}$ & 0.80 & $0.970^{* *}$ & $0.980^{* *}$ & $0.950^{* *}$ & $0.935^{* *}$ & $0.953^{* *}$ \\
\hline
\end{tabular}

*. Correlation is significant at the 0.05 level (2-tailed), **. Correlation is significant at the 0.01 level (2-tailed).

Table 5 Correlation between different physiological attributes of Gyasu rice

\begin{tabular}{|c|c|c|c|c|c|c|c|}
\hline & Salinity & FGP & GE & PDW & PL & RDW & RL \\
\hline FGP & $-0.938^{* *}$ & 1.00 & & & & & \\
\hline GE & $-0.963^{* *}$ & $0.960^{* *}$ & 1.00 & & & & \\
\hline PDW & $-0.954^{* *}$ & $0.963^{* *}$ & $0.996^{* *}$ & 1.00 & & & \\
\hline PL & $-0.965^{* *}$ & $0.992^{* *}$ & $0.972^{* *}$ & $0.977^{* *}$ & 1.00 & & \\
\hline RDW & $-0.968^{* *}$ & $0.960^{* *}$ & $0.921^{* *}$ & $0.925^{* *}$ & $0.975^{* *}$ & 1.00 & \\
\hline RL & $-0.973^{* *}$ & $0.975^{* *}$ & $0.943^{* *}$ & $0.947^{* *}$ & $0.988^{* *}$ & $0.998^{* *}$ & 1.00 \\
\hline SG & $-0.961^{* *}$ & $0.989^{* *}$ & $0.967^{* *}$ & $0.971^{* *}$ & $0.998^{* *}$ & $0.970^{* *}$ & $0.983^{* *}$ \\
\hline
\end{tabular}

*. Correlation is significant at the 0.05 level (2-tailed), **. Correlation is significant at the 0.01 level (2-tailed).

Table 6. Dry weight percentage reduction (DWPR), Salt tolerance index (STI) and Seed vigor index (SVI) for two traditional varieties rice (Chenaphool and Gyasu)

\begin{tabular}{lllllll}
\hline \multirow{2}{*}{ Salinity level (\%) } & \multicolumn{3}{c}{ Chenaphool } & \multicolumn{3}{c}{ Gyassu } \\
\cline { 2 - 7 } & DWPR (\%) & STI (\%) & SVI (\%) & DWPR (\%) & STI (\%) & SVI (\%) \\
\hline 0 & - & - & 16.75 & - & - & 8.45 \\
0. & 21.15 & 78.84 & 11.99 & -8.5 & 108.59 & 8.73 \\
0.5 & 37.5 & 62.5 & 11.39 & 34.37 & 65.62 & 2.97 \\
1.0 & 82.69 & 17.30 & 3.30 & 61.72 & 38.28 & 1.27 \\
1.5 & 92.30 & 7.69 & 1.056 & 88.28 & 1.71 & 0.34 \\
2.0 & 100 & Nil & 0.042 & 100 & Nil & 0.048 \\
\hline
\end{tabular}


Effect of Salinity on Plumule Growth

Plumule dry weight (PDW) and plumule length (PL) were maximum under the control conditions for Chenaphool, which gradually decreased with increasing salinity. In Gyasu, highest PDW and PL were recorded in $0.1 \%$ salinity. Salinity (above $0.1 \%$ to $2 \%$ ) correlated negatively with the PDW and PL. Reduction in seedling height is common phenomenon of many crop plants grown under saline conditions (Javed and Khan, 1995). Higher concentration of salts reduces the water potential in the medium which hinders water absorption by germinating seeds and thus inhibit or delay seeds germination and seedling establishment (Hakim et al. 2009).

\section{Effects of Salinity on Radical Growth}

Radical dry weight (RDW) was $4.8 \pm 0.82 \mathrm{~g}$ and $6.5 \pm 0.56 \mathrm{~g}$ for the Chenaphool and Gyasu landrace respectively under controlled conditions. Also, maximum radical length $(\mathrm{RL})$ was observed under control conditions in both the landraces. RDW and RL showed significant negative correlation with salinity. The PL and RL showed decreasing trend with increasing salinity, indicating that the salt stress not only affected germination but also the growth of seedlings, and in turn dry matter production of the seedlings (Vibhuti et al. 2015). Lower salinity stress reduces radical growth at earlier seedling stage by slowing down the water uptake (Kazemi and Eskandari, 2011), while higher salinity completely inhibits growth.

\section{Dry Weight Percentage Reduction}

Maximum dry weight percentage reduction (DWRP) was recorded at $1.5 \%$ salinity for both the landraces, while no germination was observed at $2 \%$ salinity. Lowest DWPR was observed at $0.1 \%$ salt solution in Chenaphool landrace while at $0.5 \%$ in Gyasu. DWPR (\%) showed positive relation with salinity for both Chenaphool ( $\mathrm{r}$ $=0.912)$ and Gyasu $(r=0.958)$. Reduction in the fresh and dry weight percentage reduction in the shoots than in the roots, as a result of salt stress has also been reported by Achakzai et al. (2010) and Akram et al. (2010).

\section{Salt Tolerance Index (STI)}

Salt tolerance index (STI) decreased with increasing salinity level from $0.1 \%-2 \%$ in both the landraces. In Chenaphool, STI varied between 7.69 (at 1.5\% salinity) and 78.84 (at $0.1 \%$ salinity), and $11.71(1.5 \%)$ to $108.59(0.1 \%)$ in Gyasu (Table 4). Gyasu landrace showed better STI in comparison to Chenaphool. STI in both landraces showed negative correlation with salinity (Fig. 1 \& 2). Inverse relation of STI with salinity level in the present study is in agreement with Vibhuti et al. (2015).

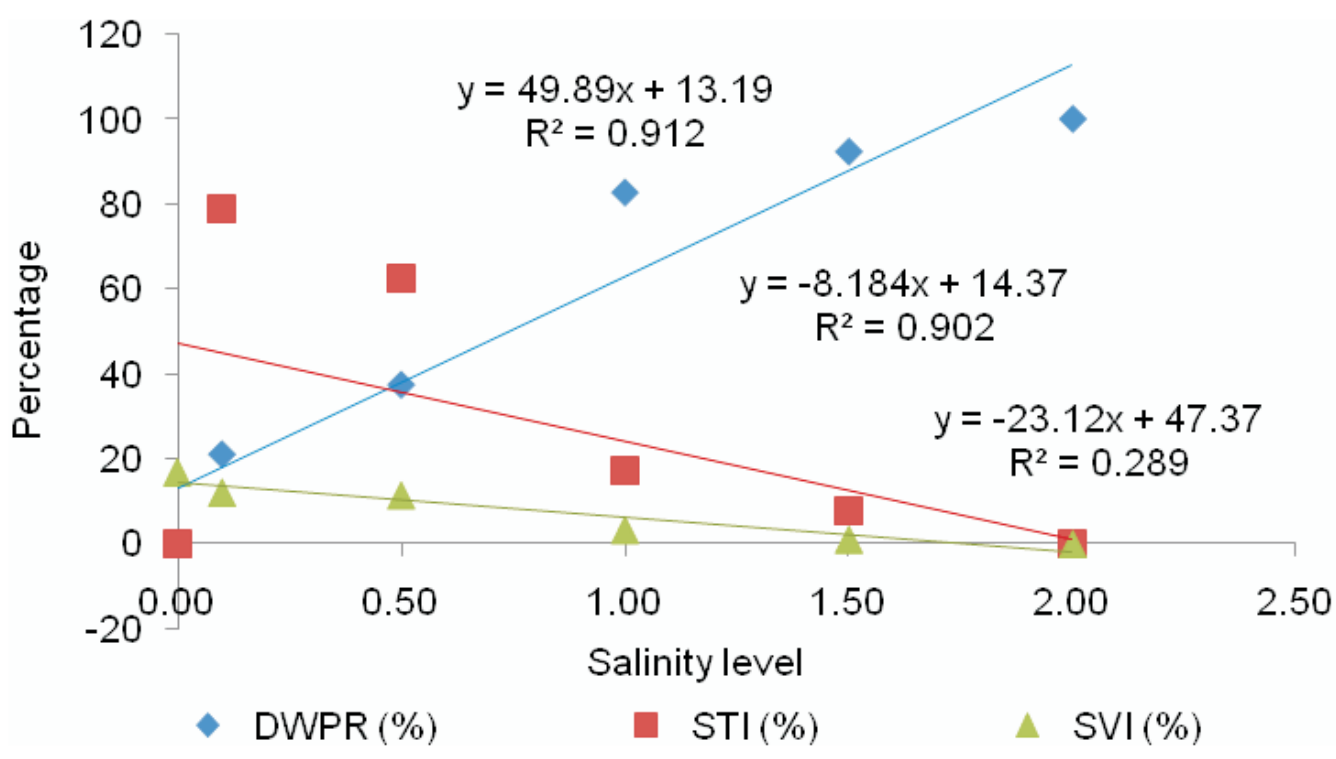

Fig. 1 Effects of salinity on DWPR, STI and SVI of Chenaphool rice 


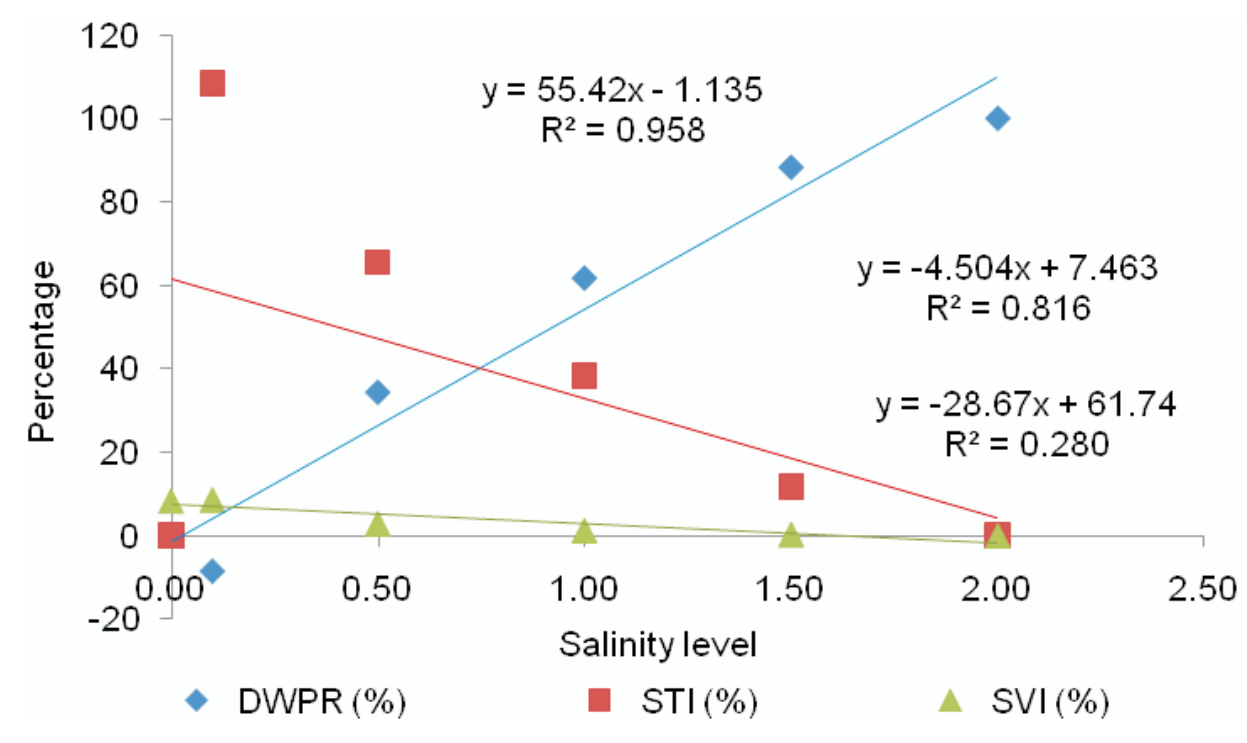

Fig. 2 Effects of salinity on DWPR, STI and SVI of Gyassu rice

Seed Vigor Index (SVI)

Seed vigor index (SVI) was recorded highest $(16.75 \%)$ in control for Chenaphool, while in $0.1 \%$ salinity level for Gyasu (8.73\%). Lowest SVI was 0.042 and 0.048 for Chenaphool and Gyasu respectively, owing to $2 \%$ salinity level. Salt stress conditions decrease water uptake during imbibitions and seedling establishment, which can then be followed by uptake of ions (Prisco and Vieira, 1976). Salinity suppresses the uptake of essential nutrients like $\mathrm{P}$ and $\mathrm{K}$ (Nasim et al., 2008), which could adversely affect seedlings growth and vigor.

\section{Conclusions}

The salinity $(>0.1 \%)$ has inverse effects on the final germination percentage, germination energy, plumule dry weight, plumule length, radical dry weight, radical length and speed of germination for two paddy landraces (Chenaphool and Gyasu). The long grained, irrigated landrace Chenaphool showed higher dry weight percentage reduction, seed vigor index but lower salt tolerance index and is more sensitive to salinity in comparison to short grained, non-irrigated landrace Gyasu. Gyasu showed very low germination than Chenaphool in general, but was more tolerant to salinity with low dry weight percentage reduction and higher salt tolerance index.

\section{References}

Achakzai, A.K., Kayani, S.A., and Hanif, Z. (2010). Effect of salinity on uptake of micronutrients in sunflower at early growth stage. Pakistan Journal of Botany 42,129-139.

Akram, M.S.A., Ashraf, R., Ahmad, E.A., Waraich, J., Iqbal, J., and Mohsan, M (2010). Screening for salt tolerance in maize (Zea mays L.) hybrids at an early stage. Pakistan Journal of Botany 42,141-151.

Almansouri, M., Kinat, J.M., and Lutts, S. (2001). Effect of salt and osmotic stress on germination in durum wheat. Plant and Soil 231, 243-254.

International Seed Testing Association (2008). 'International Rules for Seed Testing'. (Bassersdrof, $\mathrm{CH}$. Switzerland).

Asana, R.D., and Kale, V.R. (1965). A study on salt tolerance of four wheat varieties. Indian Journal of Plant Physiology 8, 5-22

Bisht, V., Singh, B., Rao, K.S., Maikhuri, R.K., and Nautiyal, A.R. (2007). Genetic divergence of paddy landraces in Nanakosi micro-watershed of Uttarakhand Himalaya. Journal of Tropical Agriculture 45 (1-2), $48-50$.

Bliss, R.D., Platt-Aloiu, K.A. and Thompson, W.W. (1986). Osmotic sensitivity in relation to salt sensitivity in 
germination of barley seeds. Plant, Cell \& Environment 9,721-726.

Chandra, A., Saradhi, P., Maikhuri, R.K., Saxena, K.G., and Rao, K.S. (2011). Traditional agro diversity management, A case study of Central Himalaya village ecosystem. Journal of Mountain Science 8, $62-74$.

Ellis, R.A. and Roberts. (1981). The qualification of ageing and survival in orthodox seeds. Seed Science Technology 9,373-409.

Gregorio, G.B. (1997). Tagging salinity tolerance genes in rice using amplified fragment Length polymorphism (AFLP). 'Unpublished Doctoral Thesis', University of the Philippines Los Baños. Laguna, Philippines. p 118.

Hakim, M.A., Jurimi, A.S., Begum, M., Ismail, M.R., and Selamat. (2010). Effect of salt stress on germination and early seedling growth of rice (Oryza sativa L.). African Journal of Biotechnology 9 (13),1911-1918.

Hampson, C.R., and Simpson, G.M. (1990). Effect of temperature, salt and osmotic potentials on early growth of wheat germination. Canadian Journal of Botany 68, 524-525.

Heenan, D.P., Lewin, L.G., and McCaffery, D.W. (1988). Salinity tolerance in rice varieties at different growth stages. Australian Journal of Experimental Agriculture 28, 343-349.

Javed, A.S., and Khan, M.F.A. (1995). Effect of sodium chloride and sodium sulphate on IRRI rice. Journal of Agriculture Research 13,705-710.

Kazemi, K., and Eskandari, H. (2011). Effect of salt stress on germination and early seedling growth of rice (Oryza sativa) in rain. African Journal of Biotechnology 10 (77), 17789-17792.

Khan, M.S.A., Hamid, A., and Karim, M.A. (1997). Effect of sodium chloride on germination and seedling characters of different types of rice (Oryzasativa L.). Journal of Agronomy and Crop Science 179,163-169.

Kumar, V., Shriram, V., KaviKishor, P.B., Jawali, N., and Shitole, M.G. (2010). Enhanced proline accumulation and salt stress tolerance of transgenic
Indica rice by over-expressing P5CSF129A gen. Plant Biotechnology Reports 4 (1),37-48.

Lutts, S., Kinet, J.M., and Bouharmont, J. (1996). NaClinduced senescence in leaves of rice (Oryza sativa L.) varieties, differing in salinity resistance. Annals of Botany 78, 389-398.

Maas, E.V., and Hoffman, G.J. (1977). Crop salt tolerancecurrent assessment. Journal of the Irrigation and Drainage Division 103,115-134

Maikhuri, R.K., Rao, K.S., and Semwal, L.R. (2011). Changing scenario of Himalayan agroecosystem, Loss of agrobiodiversity, an indicator of environmental change in central Himalaya, India. Environmentalist 20, 23-39.

Mani, S.S. (2016). Rice in Uttarakhand, http,//www.rkmp.co.in/sites/default/files/ris/ricestatewise/Status $\% 20$ Paper $\% 20$ on $\% 20$ Rice $\% 20$ in $\% 2$ 0Uttarakhand.pdf.

Michael, D., Peel, B., Waldron, L., and Kevin, B. (2004). Screening for salinity tolerance in Alfalfa. Crop Science 44, 2049-2053.

Mondal, T.K., Bal, A.R., and Dal, S. (1988). Effect of salinity on germination and seedling growth of different rice (Oryza sativa L.) varieties. Indian Society of Coastal Agricultural Research 6, 91-97.

Nasim, M.R., Qureshi, T., Aziz, M., Saqib, S, Nawaz, S.T., and Pervaiz, S. (2008). Growth and ionic composition of salt stressed Eucalyptus camaldulensis and Eucalyptus teretcornis. Pakistan Journal of Botany 40, 799-805.

Negi, V.S., Maikhuri, R.K., Rawat, L.S., and Bahuguna, A. (2009). Traditional agriculture in transition, A case of Har-Ki Doon Valley (GovindPashuVihar Sanctuary and National Park) in Central Himalaya. International Journal of Sustainable Development \& World Ecology 16 (5),313-321.

Prisco, J.T., and Vieira, G.H.F. (1976). Effects of $\mathrm{NaCl}$ salinity on nitrogenous compounds and proteases during germination of Ligrrasinensis seeds. Acta PhysiologiaePlantarum 36, 317-320. 
Ruan, S., Xue, Q., and Thlkowska, K. (2002). Effect of seed priming on germination and health of rice (Oryza sativa L.) seeds. Seed Science Technology 30, $451-458$.

Sahi, C., Singh, A., Blumwald, E., and Grover, A. (2006). Beyond osmolytes and transporters, novel plant saltstress tolerance-related genes from transcriptional profiling data. Acta Physiologiae Plantarum 127, 1-9.

Sati, V.P. (2005). System of agriculture farming in the Uttaranchal Himalaya, India. Journal of Mountain Science 2,76-85

Siddiq, E.A., Viraktamath, B.C., Bentur J.S., and Kumar, S. (2009). 'Handbook of Agriculture'. (Indian Council of Agricultural Research, New Delhi).p. 964.
Tuteja, U. (2013). Agriculture Profile of Uttarakhand. Agricultural Economics Research Centre University of Delhi.

http,//www.du.ac.in/du/uploads/Academics/centres institu tes/Agricultural_Eco/16.2013Agri\%20profile\%20o f\%20Uttrakhand-\%20Usha\%20Tuteja.pdf.

Vibhuti, S. C., Bargali K., and Bargali, S.S. (2015). Seed germination and seedling growth parameters of rice (Oryza sativaL.) varieties as affected by salt and water stress. Indian Journal of Agricultural Sciences 85 (1), 102-108.

Received: December 2016 Accepted: February 2017 